\title{
Study on the Features of Textile Industry Cluster in Guangzhong
}

\author{
Tong Yang \& Meilin He \\ School of Management, Xian polytechnic University, Shaanxi, China \\ E-mail: yangtong1268@163.com
}

This paper is supported by Textile economy special subject.

\begin{abstract}
Xi'an and Xianyang is two famous textile towns in Guangzhong, it formed a cotton textile industry-oriented research, production systems and international market networks which have great influence throughout the country. The textile industry cluster in the region is now in cluster development infancy, being a free competitive market structure. According to the cluster features it explores the main form factors: Well-known local entrepreneurs, social networks and local government. Then it brings forward the corresponding development strategies: 1) nurturing local entrepreneurs, building networks and strengthening local industry local government's macro-control and service functions; 2) Selecting gathering space-based development model.
\end{abstract}

Keywords: Guangzhong, Textile industry cluster, Strategy

1. Determine to the Evolution Stage of Textile Industry Cluster in Guanzhong Area

\subsection{Model Construction}

The dynamic development of industrial clusters usually goes through the following four stages: (1) Period of free competition, in which corporate scale in industrial clusters is same and cooperative relationship between enterprises is not stable. (2) Period of low concentrate competition, in which some larger enterprises began to appear in Clusters and the degree of work specialization among enterprises, is higher than before. (3) Period of high and medium Oligopoly, in which large companies or multinational corporations having considerable influence in clusters have emerged, and cooperative relationship between enterprises and intermediaries is stable and abundant. (4) Period of extremely high Oligopoly, in which one or two big companies control the development of entire cluster, and others or to follow, or to withdraw from the market. Therefore, according to the dynamic changes of market structure type, the corresponding evolution stages of cluster are: embryonic period, development period, take-off period and mature stages. Dynamic analysis of Industrial cluster developmental stages is used as a quantitative determination method reflecting the degree of industrial organization and evolution stage through market concentration of sellers. Economists Bain is the first person who analysis the dynamic evolution of the industry cluster by using market concentration. Its theoretical basis is that business develop or is eliminated under the role of competition mechanism. Market concentration develops in ascendant trends. This method is relatively scientific and reasonable, and is widely used to measure the developmental level of clusters. For this reason, this paper judges the level of cluster development in Guangzhong area by adopting the indicator system. The formula is below:

$$
C R_{n}=\frac{\sum_{j=1}^{n} X_{j}}{\sum_{i=1}^{m} X_{i}}
$$

In this formula, $\mathrm{CRn}$ is market concentration of pre-n firms in cluster. $X_{\mathrm{i}}$ is No.i-bit enterprise's in cluster output value, sales revenue, volume of sales, number of employees and total assets value,etc. $\sum_{j=1}^{n} X_{j}$ is for certain indicator's sum of pre-n firms of the largest scale in cluster. $\sum_{i=1}^{m} X_{i}$ is for certain indicator's sum of all firms in cluster. $\mathrm{n}$ is 4 or 8 . According to Bain's research on the degree of industrial organization or the definition of market structure, the article puts forward the decision method of industrial clusters which is based on the market concentration. See Table one. 


\subsection{The Evolution Determine Stage of Industrial Clusters}

Guangzhong has two famous textile cities of the nation: Xi'an and Xianyang, which forms scientific research, production systems and international market network dominated by cotton textile industry. 80 percent of the cotton spinning enterprises pass the national IS09000 quality system certification and are influential throughout the country. In 2005, textile industry of Shaanxi had a total of 93 textile enterprises and achieved the output value of 5.735 billion yuan. The top eight companies of annual output value were: Tang Hua four cotton, Tang Hua five cotton, Five Rings Group, The first national cotton factory, The second national cotton factory, Tian Gong Xing Ye Group, Cotton Plant of Shaanxi 9 Factory and Shaanxi Textile Industries. Theirs annual output value was: 1.62, 1.48, 1.33, 1.30, 1.21, 1.18, 1.16 and 1.09 million yuan. Accordingly, we can determine the evolution stage of textile cluster in Shaanxi Province:

$$
\begin{aligned}
& \mathrm{CR}_{4}=(1.62+1.48+1.33+1.3) / 57.35 \times 100 \%=9.9913 \% \\
& \mathrm{CR}_{8}=(1.62+1.48+1.33+1.3+1.21+1.18+1.16+1.09) / 57.35 \times 100 \%=18.082 \%
\end{aligned}
$$

According to Bain's determine standard of evolution stages of cluster: $\mathrm{CR}_{4}<30 \%, \mathrm{CR}_{8}<40 \%$, we can find the textile industry cluster in Guanzhong lies in embryonic stage and the market structure belongs to free competition.

\section{Characteristics and Forming Factors of Textile Industry Cluster in Guangzhong Area}

\subsection{Clustering Feature}

Textile industry in Guanzhong area spontaneously formed cluster, because the area can integrate local factor endowment advantage with historical and cultural factors. Meanwhile, it relied on local endogenous strength. The textile industry belongs to typical Spontaneously Industrial Clusters ${ }^{[1]}$. The occurrence and development of industrial clusters experience a process of natural selection and historical evolution. It has some characters as follows:

1) Embeddedness. Embeddedness emphasizes trust and cooperation among economic entities in cluster. In spontaneously, industrial Clusters, every economic subject is easy to form interdependent industrial association and a common industrial culture, and form a system which restricts People's behavior. Under the system's restriction, people's new ideas, new concept, information and innovation spread faster, result in saving the transaction costs of inter-enterprise. Because acquisition of own competitiveness in the clusters relies mainly on exertion of the whole advantage of cluster, the trust and cooperation which demonstrated in the action permeates every corner of the cluster. In the cooperation, there are some equal and informal characters.

2) Symbiosis. Symbiosis is a kind of phenomenon which different kinds of biology live together. Socioeconomic phenomenon is similar to biosphere in many ways. Spontaneously Industrial Cluster is actually a symbiotic system organization. It is similar to bioecosystem and is based on work specialization and social coordination. Also it is an ecological enterprise group of symbiotic complementation of different kinds of enterprises. As the co-existence of biological populations is also competitive and cooperative, however, this competition frequently enables enterprises to maintain sufficient impetus. Function is complementary among businesses in cluster, which leads to most enterprises having a wider space for development. Facts have proved that large and small enterprises developing isolatedly would not beneficial to achieve the optimal allocation of regional resources. However, the formation of the symbiotic tissue system of large and small enterprises and establishment of trust relationship between enterprises can not only reduce the risks of uncertainty but also reduce the transaction costs brought about for isolated development.

\subsection{Major Factors of Forming Cluster Characteristics}

Based on spontaneously industrial cluster's characteristics in Guanzhong area, core elements promoting the growth of industry cluster are local well-known entrepreneurs, social networks and local government. A combination and change of three jointly promote the formation, development and evolution of industrial clusters.

\section{1) Local Well-known Entrepreneurs}

Local well-known entrepreneurs usually have stronger social skills, rich social relations and a strong marketing ability. The formation of spontaneously industrial cluster is often a catalytic result of profit-maximizing behavior and interaction of economic agents, and local entrepreneurs. In early days of cluster formation, maybe accidental innovation activity of individual enterprises form new market after achieving commercial success, which lead to industrial clusters sprouting. Strong externalities of entrepreneurial activity lead to successful economic activity being imitated and followed. Meanwhile, volume of business of related products' production and operating activities gradually increase too. After lots of enterprises which produce the same type of product get together in 
a certain region, it can gain Economic of Scale. So that the productivity of entire region will be improved, and also give rise to a industry cluster which is rich in regional competitive.

2) Social Network. Social network is defined as the total sum of social and individual relationship in social groups. Local industrial clusters are not simply business combination but regional network of Specialization and Cooperation .First, social network provides an important platform of cooperation and trust for building a regional network. The collective benefits it produces make single workshop overcome weaknesses of small scale production. Further more, in a not developed region of market economy, social network helps enterprises in Industry Cluster, other social and economic research and political institutions to build necessary trust. So that they can get finance, technology, raw materials and all kinds of information closely related to operating from the community, surrounding cities and even other parts of the country, and can continuously open up new markets. Second, Social network promotes reproduction and differentiation in cluster. Detailed Industrial Division in the region reduces capital threshold of entrant. Inter-enterprise transaction costs have been reduced because the division of labor is build on social network based on descent, affinity and landras (Lin, Jingjun, 2004).

3) Local Government. The initial scale of enterprises in Spontaneously Industry Cluster is generally smaller. Corporate behavior has a more speculative and short-term. The speculative and short-term behavior cause incomplete information. Forecasting errors of growth and trend of market will lead to seriously surplus productivity, so as to trigger a price-based vicious competition which makes market be flooded with fake and shoddy products. As a result, the healthy development of industrial clusters is affected. Therefore, formation and development of Spontaneously Industry Cluster need government to support and guide. The Government have some effects on textile industry of Guangzhong, which are mainly reflected in the provision of public infrastructure, the formulation of policy stimulating the development of local industrial clusters, the support of technological development, the protection of intellectual property, the establishment of trade associations and other intermediary organizations, the regulation of market behavior and product quality standards, the promotion of regional brands and so on.

A combination of the above three factors restricts the development of clusters. In different periods of cluster development, various factors play different roles. In early stage of the development of textile industry cluster, social networks link closely tens of thousands of family workshops, purchases and seller to market, which make up a large industrial network. However, local governments are basically at the "inaction" state by this time. When industrial cluster get into the period of rapid expansion, the rapid growth of innovative entrepreneurs promote enterprise-scale structure in cluster differentiate. Increased competition of market brings urgent needs of market norm and various infrastructure facilities, which make local government, take intervention measures passively. When the cluster gets into the period of steady development, cluster is faced with strong competitive pressure from the international market. Increasing demand for product quality, product technology and enterprise management strengthens the combined action among the entrepreneurs, local governments and social networks.

\section{The Sustainable Development Countermeasure of Textile Industry Cluster in Guangzhong Area}

The growth pattern's feature of spontaneously textile industry cluster in Guangzhong area makes traditional industries present following characteristics in China's regional development. That is, after traditional industries with not high technical content assemble in some area, strengthening the level of specialization and collaboration capability can greatly enhanced the content of Knowledge Economy of traditional industries and gradually evolves into knowledge-intensive industries, which make it have an advantage of increasing revenue (Liu and Chen, 2004). Therefore, promoting the development of local spontaneously industry cluster is benefit to excavate the potential of traditional industries.

1) Nurturing local entrepreneurs, building local industry networks, and enhancing local government's macro-control and service functions. Local entrepreneurs are not only important subjects of local industrial network but also important human resources promoting the development of cluster. Entrepreneurs group's foundation and innovation activity in technology and system not only decide the growth path of corporate, but also have a profound impact on the network members through their social networks. Ultimately they affect the development path of the cluster. The key reason why backward areas fall behind is that these areas are lack of innovative entrepreneurs. At a deeper level to see, it is lack of local social culture which promotes the growth of entrepreneurs. Social network is the basis for building a spontaneously industry clusters. The same cultural background and psychological habits, similar social relations and common social norms are benefit to build confidence between enterprises and reduce transaction costs. Meanwhile, social networks also link to different industrial network to facilitate informal exchanges and co-operation between individuals so as to enhance innovation opportunities for local industrial clusters (Grabber, 1993).At the same time, moderate involvement of local governments is necessary and effective for the development of local industrial clusters. In addition to the 
traditional functions of local government, it may also extend to the updated service areas, such as the implementation of regional marketing strategies, the construction of innovation environment and the establishment of social credit system. Furthermore, when local governments formulate industrial policies and regional development planning, they should gradually turn a variety of preferential policies from simple directing to the areas to direct to technology of clusters and industry, so that various of factors of production inter-regional can natural flow and develop industrial clusters with local characteristics.

2) Choice the Development Pattern of Spatial Agglomeration

It is a development pattern which is usually adopted by

Primary industry .This pattern not only achieve complementary in line operation but also bring the external economies of scale for enterprises which share infrastructure when collection is considered as a resource configuration or spatial form of layout. All of these are benefit to carry out professional collaboration, and exchange and spread of information. Every corporation in Spatial Agglomeration Industrial Cluster is a independent producer linked by the market internally, and externally, plays a large enterprise's function together. Guanzhong area with Xi'an and Xianyang two famous textile city had an abundant strength in Textile Industry. In a limited geographical area, the area concentrated a number of key and affective enterprises such as Tang Hua four cotton, Tang Hua five cotton, Five Rings Group, The first national cotton factory, The second national cotton factory, Tian Gong Xing Ye Group, Cotton Plant of Shaan 9 Factory, etc which formed research, production systems and the international market network based on cotton textile industry. In recent years, the textile industry in Guanzhong area intensified technological transformation, accelerated the development of deep processing production, developped industrial textiles and clothing products to meet market demand actively, optimized product structure and improved product quality and grades around greatly improving the product's international market share. At the same time, it promoted actively Enterprise Capital Reorganization, build large-scale cotton textile enterprise group, strengthened industrial integration and enhanced core competitiveness of industries. The focus on restructure of textile city of Xi'an, construction of textile industrial park in Xianyang and promotion of cotton industry of Caijiapo to speed up the organization of emerging industry clusters, promote the joint and configured development of research and production and improve the developmental effectiveness of agglomeration, which make Guangzhong become the country's largest textile industry production base of R \& D and export. It has been found that this economic model, to a certain extent, is able to overcome the "big company disease", but also has access to professional collaboration and scale economics, so as to effectively realize docking of small businesses and large markets.

\section{References}

Grabber. (1993). The embedded firms on the social-economics of industrial networks routes. London EC4P.

Lin, Jingjun. (2004). Embeddedness, Social Networks and Industrial Clusters. Economic Jingwei, (5): 45-47.

Liu, Hengjiang \& Chen, Jixiang. (2004). Study on Foreign Industrial Clusters Policy. Foreign Economy and Management, 26(11):36-43.

Wang, Bufang. (2004). Summary of Industrial Cluster Theory of Mainstream Economic School in the World. Foreign Economy and Management, 26(1):12-16.

Table 1. The Evaluation Determine Indicators of Industrial Clusters Based on the Market Concentration

\begin{tabular}{l|l|l|l}
\hline Evolution Stage of Cluster & Type of market structure & $\begin{array}{l}\text { Bain } \mathrm{CR}_{4} \\
\text { Numeric } \%\end{array}$ & $\begin{array}{l}\text { Bain } \mathrm{CR}_{8} \\
\text { Numeric } \%\end{array}$ \\
\hline Embryonic stage & Free Competition & $\mathrm{CR}_{4}<30$ & $\mathrm{CR}_{8}<40$ \\
\hline Developing Stage & $\begin{array}{l}\text { Low Concentrate } \\
\text { Competition }\end{array}$ & $30 \leq \mathrm{CR}_{4}<35$ & $40 \leq \mathrm{CR}_{8}<45$ \\
\hline Take-off Station & $\begin{array}{l}\text { High and Medium } \\
\text { Oligopoly }\end{array}$ & $35 \leq \mathrm{CR}_{4}<75$ & $45 \leq \mathrm{CR}_{8}<80$ \\
\hline Mature Stages & $\begin{array}{l}\text { Extremely High } \\
\text { Oligopoly }\end{array}$ & $75 \leq \mathrm{CR}_{4}$ & $85 \leq \mathrm{CR}_{8}$ \\
\hline
\end{tabular}

